\title{
Écija. Reflexiones en torno al Patrimonio Histórico
}

\section{Palabras clave:}

Écija / Historia del Arte/ Patrimonio/ Tutela / Destrucción / Expolio / Puesta en valor / Interpretación / Musealizacion.

Gerardo García León Historiador del Arte

\section{Resumen:}

Se exponen una serie de consideraciones acerca del patrimonio histórico de Écija desde el punto de vista del historiador del arte. También se estudian las potencialidades del patrimonio histórico de la ciudad, los problemas derivados de su tutela y se proponen iniciativas para su rentabilización social.

\begin{abstract}
A la hora de ofrecer una visión del estado en que se encuentra Écija respecto al tema que nos ocupa, seguiremos el orden teórico del proceso de la tutela del patrimonio histórico, si bien éste es una simplificación de la complicada interacción que, en la práctica, se produce entre su protección, conservación, investigación y difusión. Conviene recordar -aunque sea ya un lugar común- que es ésta, en ese plano ideal, la que otorga al proceso un carácter cíclico, al ser principio y fin del mismo.
\end{abstract}

Todas las medidas y acciones de protección, conservación e investigación deben desembocar en la difusión, que incluye de manera muy especial la educación en el conocimiento y valoración de nuestros bienes culturales. Un mayor aprecio colectivo de éstos provoca y desencadena el incremento de la protección y, por tanto, el inicio de nuevos procesos de tutela. Coincidimos con las afirmaciones de Concha San Martín cuando expresa que los objetivos básicos de la difusión del patrimonio son: la democratización del acceso a los bienes culturales, la rentabilización del patrimonio cultural de la comunidad en términos de disfrute y recreación para todos y la educación de todos los sectores sociales en el conocimiento y la estima de unos bienes culturales que son parte esencial de una identidad común !.

Es bien sabido que la situación natural y el entorno geográfico de Écija siempre han favorecido el establecimiento de pueblos y el desarrollo de actividades agrícolas, ganaderas, comerciales, etc. Esta ubicación en una amplia y rica llanura, a orillas del río Genil, hizo que pronto se constituyera como un hito impor- tante en los principales caminos y vías de comunicación de la comarca. El primer momento de esplendor vivido por la ciudad se remonta a época romana. Son muy importantes los vestigios arqueológicos de esta civilización que continuamente siguen apareciendo en el subsuelo de la ciudad y de su término municipal. Aunque de menor relevancia, también son frecuentes los hallazgos del periodo en que se mantuvo la dominación musulmana. Pero, sin duda, serán la sociedad y cultura cristianas, las que mayor número y calidad de manifestaciones artísticas y patrimoniales dejen a la actual ciudad de Écija.

El nuevo régimen de corte occidental y feudal, nacido tras la conquista en 1240, puso las bases de un nuevo sistema de vida en el que las relaciones sociales, comerciales y culturales van a propiciar el desarrollo de un núcleo urbano potente, atractivo para los asentamientos dispersos en los que por entonces se repartía una parte importante de la población de la zona. Este desarrollo se verá favorecido por motivaciones político-militares, -Écija se hallaba bajo jurisdicción real y era una de las ciudades que tenía voto en Cortes- y por su situación en las proximidades de la frontera con el decreciente poderío musulmán.

Mientras todo esto ocurría, se fue produciendo el lógico proceso de sustitución de funciones en gran parte de los edificios más importantes de la población. La implantación de iglesias cristianas en las mezquitas motivó la temprana realización de sustanciales reformas en los edificios musulmanes. El aumento de la población y la necesidad de crear nuevas iglesias que se alzaran como testimonios triunfales de la verdadera fe, provocó un proceso de sustitución de las fábricas musulmanas por nuevas obras de estilo gótico, si bien con claras manifestaciones mudéjares, que también afectó a los escasos recintos destinados al culto hebraico.

Por otro lado, las edificaciones de uso comercial, administrativo y militar debieron seguir en uso. Aunque gran parte del caserío abandonado por los musulmanes fue reutilizado por la población cristiana, el lento pero progresivo cambio de las costumbres hizo que fueran perdiendo su función edificios como los baños públicos, madrazas, etc; en cambio, otros mantuvieron e incluso aumentaron su importancia para la ciudad, como el complejo sistema defensivo integrado por la muralla y el alcázar situado en el altozano del Picadero.

Otro factor que contribuyó notablemente a la transformación urbana de la Écija cristiana fue el número creciente de fundaciones conventuales llevadas a cabo desde la Baja Edad Media y, sobre todo, a partir del siglo XV. Exclusivamente patrocinadas por la nobleza local, componen el habitual elenco de órdenes 


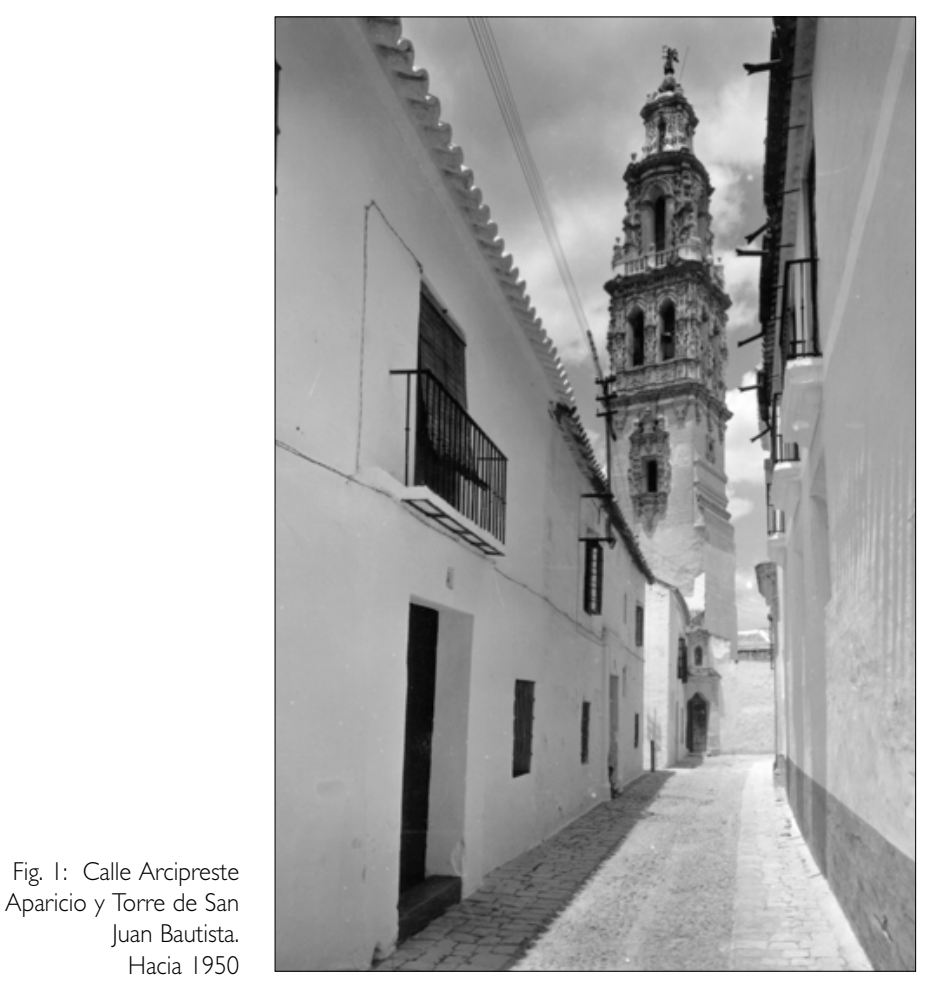

religiosas que gozaban del mayor prestigio y popularidad: franciscanos, dominicos, carmelitas, agustinos, jerónimos, mínimos, mercedarios y jesuitas. Estas fundaciones, protagonizadas por las oligarquías locales, también se vieron favorecidas por el propio concejo municipal que, en todo momento, mostró su colaboración y apoyo a la erección de los nuevos conventos y monasterios.

Como resultado de todo este proceso, a mediados del siglo XVIII y con una población que rondaba los 30.000 habitantes 2, Écija contaba con seis parroquias, diecinueve conventos de frailes y monjas de clausura, seis hospitales con sus instalaciones asistenciales y capillas, dos oratorios públicos servidos por eclesiásticos y diez ermitas, repartidas por el casco urbano y sus inmediaciones. A este importante conjunto monumental habría que añadir los numerosos palacios, casas solariegas y mansiones señoriales que servían de residencia a la nobleza local, así como un número destacado de grandes caserones habitados por hacendados, comerciantes enriquecidos, clérigos y funcionarios. Trascendiendo la categoría de lo monumental, no se debe olvidar la riqueza presente en multitud de elementos patrimoniales más humildes que servían de morada a la mayor parte de la población y que, tomados en su conjunto, también resultan esenciales para el conocimiento e interpretación del pasado.

\section{Recursos patrimoniales de la ciudad y su territorio}

Atendiendo la clasificación aceptada entre los diferentes tipos de patrimonio, reseñamos en primer lugar el patrimonio arqueológico. La dificultad que entraña el acceso a este tipo de patrimonio limita nuestro conocimiento a los hallazgos fortuitos de restos arqueológicos y a aquéllos recuperados mediante las excavaciones de urgencia que, desde los últimos veinte años, se vienen realizando en el casco urbano Écija ${ }^{3}$. También son constantes los descubrimientos en el extenso término municipal, destacando los yacimientos de Alhonoz, Cerro de las Balas,..., etc. así como los numerosos alfares que jalonan las riberas del río Genil hasta su desembocadura. Las piezas recuperadas en estas excavaciones urbanas, junto a hallazgos casuales y a otras, procedentes de colecciones particulares se conservan actualmente en los Museos Arqueológico de Sevilla e Histórico Municipal de Écija, así como en la Colección Arqueológica de la parroquia de Santa María. La excavación extensiva que en la actualidad se lleva a cabo en la Plaza Mayor, como medida cautelar ante la pretensión municipal de construir un aparcamiento subterráneo, está deparando novedosos descubrimientos, entre los que destacan unas termas romanas -con la aparición de una interesantísima escultura de Amazona Herida 4 , con restos de policromía- y una necrópolis musulmana, con cerca de 3.000 enterramientos.

Por lo que respecta al patrimonio arquitectónico, debemos distinguir dos tipologías básicas: arquitectura civil y religiosa. La arquitectura civil ecijana constituye actualmente uno de los conjuntos edilicios más relevantes de la provincia de Sevilla. Pese al gran número de edificaciones desaparecidas, Écija mantiene en muchos de sus barrios la trama urbana de origen islámico y aún continúa conservando una parte significativa de su caserío. En palabras del Avance del Plan Especial de Protección, Reforma Interior y Catálogo del Centro Histórico, "Écija se ha caracterizado por la preponderancia de una edificación bastante neutra, con fachadas encaladas de una o dos plantas, con escasas complicaciones en su composición y tratamiento de huecos y una gran austeridad en el tratamiento de los materiales. Sobre este fondo continuo y neutro que son las fachadas de las calles de la ciudad, iban destacando los palacios e iglesias en fuerte contraste con el entorno, un juego de contrapuntos donde la singularidad, a veces abundante, se ponía en valor frente al caserío popular que le acompañaba, de forma similar a tantos pueblos de la región" 5.

La casa-patio tradicional ecijana reproduce el esquema presente en gran parte de Andalucía. De inspiración romana y con claras huellas de la cultura musulmana, este tipo de vivienda mediterránea se caracteriza en Écija por la existencia de un zaguán a la entrada, delimitado por el portón de madera que garantiza la intimidad del resto de la casa; será a partir de la segunda mitad del siglo XIX, cuando los portones vayan dejando paso progresivamente a las características cancelas de hierro -forjado al principio y fundido con posterioridad- que, con su transparencia, abrirán el patio a la mirada del curioso o del visitante.

Como es lógico, el patio es el elemento definitorio de la casa ecijana. De dimensiones variables, su mo- 
numentalidad está condicionada por el rango social y económico del dueño de la casa. Con evidente funcionalidad, al proporcionar luz natural y ventilación, en ocasiones está decorado con fuentes de piedra o surtidores que, unidos a la presencia de las plantas, hacen de este lugar un espacio agradable y acogedor, especialmente en la estación calurosa. Suele tener forma cuadrada o rectangular y sus frentes muestran, por lo general, galerías de arcadas sobre columnas de mármol o piedra caliza de Estepa; las plantas superiores reproducen el mismo esquema, si bien, las arcadas generalmente aparecen cegadas por tabiquería perforada con balcones, para proteger los pisos superiores de las inclemencias del tiempo. Menos frecuentes son los patios flanqueados por arcos sobre pilares ochavados de ladrillo de inspiración mudéjar y lo mismo ocurre con las columnas construidas a base de ladrillos curvos, ingeniosa y barata solución constructiva de la que existen antecedentes de época romana.

En torno al patio se organizan las diferentes habitaciones de la vivienda; si las dimensiones del edificio lo requieren, se agregan nuevas crujías que suelen abrirse a patios traseros y secundarios.

Incluso durante la época barroca, las fachadas de las casas ecijanas son de gran sobriedad y pureza de líneas. La disposición de los vanos está condicionada por las necesidades interiores y no respeta un orden preestablecido. Será a partir del siglo XIX cuando la racionalidad se imponga, y aparezca una cierta normalización en la apertura y tipología de vanos, llegando a sustituirse fachadas completas por considerarse anticuadas ${ }^{6}$. En función de las estéticas imperantes en cada época y del poder adquisitivo de sus dueños, las casas pueden estar dotadas, además, de portadas suntuosas, vanos guarnecidos de adornos de cantería o de ladrillo cortado, fachadas cubiertas de esgrafiados ricamente policromados, galerías de arcadas superiores y torreones miradores, que añaden valores monumentales a los edificios y proclaman el prestigio social de sus moradores.

Los materiales de construcción son los habituales en esta zona de la campiña andaluza: el ladrillo, la cal, el tapial y la piedra, ésta última casi exclusivamente reservada -por su escasez- a los fustes y capiteles de columnas, ménsulas, jambas y rebates (palabra muy usada en Écija para designar el escalón o umbral que sirve de entrada a una casa). Las cubiertas de la casa tradicional están formadas por armaduras de madera de diversa complicación, que soportan el tendido por tabla y las tejas curvas del exterior; no es infrecuente la presencia de alfarjes en edificios civiles.

Como ejemplos significativos de la casa descrita, podemos citar los edificios situados en la calle José Canalejas $n^{\circ} 2$, del Conde $n^{\circ} 28$, de los Caballeros $n^{\circ}$ 38 y 43 , Mayor $n^{\circ} 16$.

La constante presencia de nobleza en Écija desde época medieval motivó que este potente grupo social fijara su residencia en edificios de especial categoría, que abarcaban desde grandes caserones dotados de unas mínimas condiciones de confort y lujo, hasta verdaderos y complejos palacios, dignos de una ciudad de primer rango. Partiendo, en la mayoría de los casos del modelo de casa anteriormente descrito, se produce un aumento significativo de las dimensiones de la edificación y sobre todo, un empleo sistemático de materiales constructivos de gran calidad y solidez. El zaguán doméstico es sustituido por un espacio semicubierto que recibe al visitante y se denomina "apeadero"; a él se abren las caballerizas, algunas dependencias de servicio o vigilancia y la entrada a la zona privada de la residencia, que suele estar precedida por una portada noble o una gran escalera monumental.

La distribución interna de estos palacios reproduce, a gran escala, la estructura de las casas locales. El lujo y la ostentación se apoderan de salones, comedores y aposentos, que se cubren con artesonados de ricas maderas y se visten con las mejores galas y ornamentos que la posición social de sus dueños puede costear; pero además, aparecen otras estancias originadas por una funcionalidad concreta, como son los oratorios, salas de armas, o los estrados, cuartos principales de la casa, destinados a la recepción de los visitantes. También los patios se enriquecen con adornos de azulejos, paramentos policromados, fuentes $y$ esculturas que, a veces, se extienden por otros patios secundarios y jardines.

Complemento de estas residencias palaciegas son las dependencias de servicios que, en segundo término y alejadas de las zonas áulicas, constituyen su apoyo básico. Se trata de las cocinas, lavaderos, dormitorios y cuartos de los servidores, graneros, pajares y corrales, que pueden estar dotados de huertas con sus norias y albercas.

Son relevantes ejemplos de cuanto acabamos de describir el palacio de los condes de Palma -notable palacio mudéjar transformado durante el siglo XVII en convento de clausura- y el del conde de Valhermoso de Cárdenas -con fachada plateresca, columnas y capiteles romanos de acarreo y grandes reformas decimonónicas-. Durante el siglo XVIII fueron construidos - ampliados los palacios de los marqueses de Peñaflor7, de Benamejí, de las Cuevas del Becerro, de Quintana de las Torres ${ }^{8}$ y de Sauceda, entre otros.

Pero en Écija existen otros edificios de uso civil, construidos con una funcionalidad específica; son las llamadas casas-miradores. Ubicadas en la Plaza Mayor y aledaños, estaban destinadas a servir de tribunas desde las que poder contemplar aceptablemente los acontecimientos y espectáculos que tenían lugar en la plaza. Poseen una morfología característica: edificios con gran desarrollo en altura, construidos sobre soportales, con fachadas casi completamente perforadas por balcones y ventanales. Los más relevantes son los que pertenecieran a los marquesados de Peñaflor y Benamejí, el que se levanta adosado a la iglesia de San Francisco y el del Gremio de la Seda, erigidos o renovados todos durante la segunda mitad del siglo XVIII. 

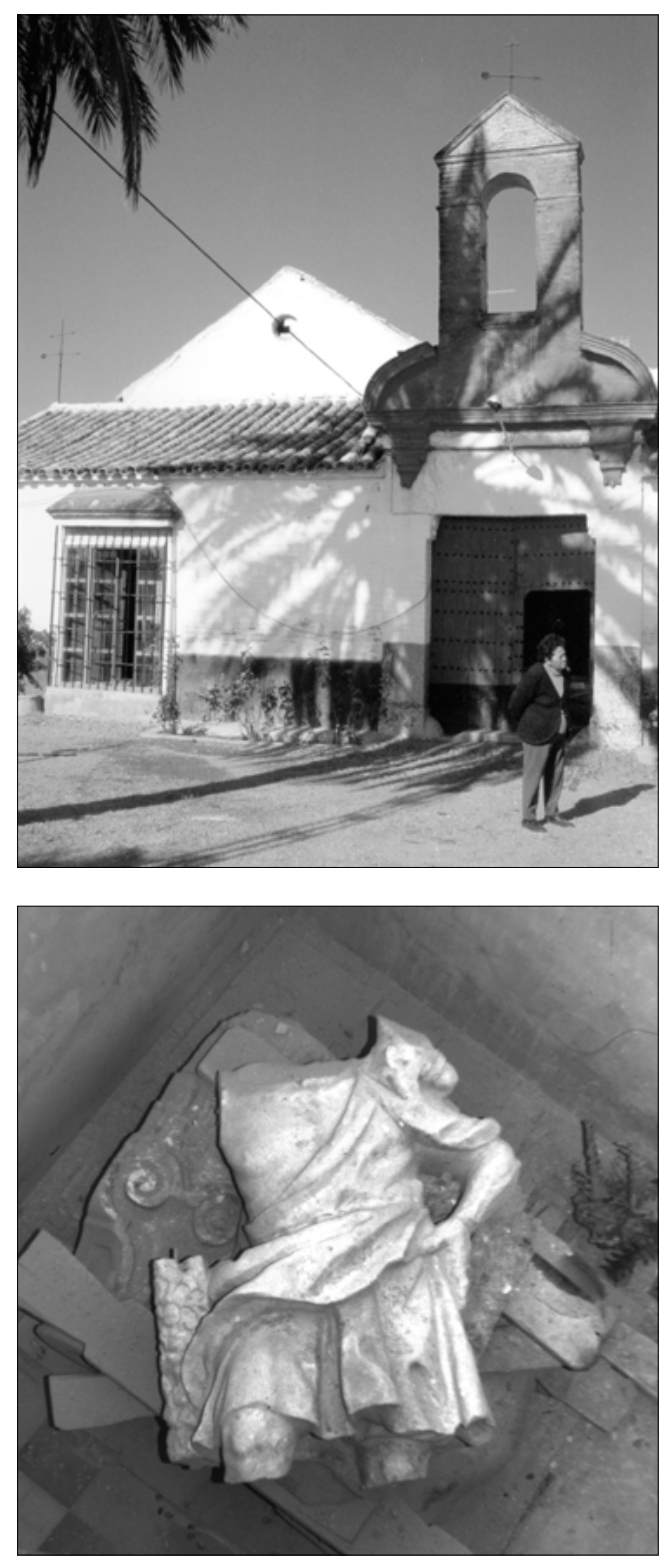

Hay que fijar nuestra atención, así mismo, sobre el patrimonio disperso en el ámbito rural ecijano. Los cortijos, molinos, haciendas y casas de labor que en otro tiempo constituyeron piezas básicas de la explotación agropecuaria, hoy se hallan en franco proceso de desaparición; a su valor arquitectónico unen un evidente interés histórico, etnológico y cultural. Estos inmuebles suelen estar organizados en torno a un patio central flanqueado por edificaciones, cuyas características vienen determinadas por su funcionalidad específica. En el término municipal de Écija son muy abundantes las almazaras, edificios de una o dos plantas, dotadas de naves de molienda y de la viga, con su torre de contrapeso; a su vez, poseen almacenes, cuadras, pajar y viviendas. Aún mantienen gran parte de su esplendor los molinos del Caño, Fuente de los Cristianos, la Alberquilla, la hacienda de San Francisco y el lagar de San Isidro (quizá el único lagar conservado en el término municipal de Écija).

En el campo de la arquitectura pública urbana, primeramente hay que señalar por su antigüedad y di- mensiones la Muralla medieval; de origen almohade, pero muy rehecha en época cristiana, hoy en día está reducida a un conjunto fragmentario de lienzos, torreones y torres albarranas que aún permiten intuir la importancia de este recinto militar. Relacionados con dicho recinto son los restos que, pertenecientes al antiguo Alcázar, actualmente se excavan en las proximidades de la parroquia de San Gil; en este lugar probablemente deberán encontrarse las huellas más antiguas del poblamiento astigitano.

Écija posee, aunque maltrecho y mutilado, el edificio de las antiguas Carnicerías Reales, construcción diseñada por Hernán Ruiz III, con importante portada manierista fechada en 1572. De la misma época es el Arca Real del Agua, construida con motivo de las obras de abastecimiento de agua a Écija, a cargo del citado arquitecto cordobés En el interior del Casino Ecijano se han reutilizado los restos del antiguo Pósito de la ciudad. Aunque muy reformado, el Puente sobre el río Genil data del siglo XVIII.

También se halla muy modificado el edificio del Ayuntamiento, heterogéneo conjunto de construcciones de diferentes épocas y tipologías, al que el arquitecto Balbino Marrón y Ranero dotó de una fachada unitaria en 1863. Las fuentes y monumentos que adornaron en otras épocas las calles y plazas de Écija hoy empiezan a ser un recuerdo. Se mantienen las fuentes de la plaza del Matadero (1695), la de Cañato (1778) -en la calle Empedrada- la de los Delfines (1778) -en la plaza de Puerta Cerrada-y la de la plaza de Colón (1937). Restan, así mismo, una fuente mudéjar del siglo XVI en los inicios del camino a Osuna -la Fuensanta- y otra muy reformada en época neoclásica, situada al comienzo de la carretera de Lucena -las Peñuelas-.

Perviven aún los Triunfos dieciochescos de San Pablo (1772), en el paseo del mismo nombre y el de la Virgen del Valle (1766), en la plaza de Santa María. En el Museo Histórico Municipal se conservan los fragmentos del Triunfo de San Cristóbal (inaugurado en 1750 y derribado, al igual que las puertas de la Muralla, por mandato de la Junta Revolucionaria de 1868) y las esculturas mutiladas de las cuatro Ninfas de una fuente que existió hasta 1866 en la Plaza Mayor. Inexplicablemente y como hecho insólito, inadecuado y lamentable, dichas esculturas, al igual que otros restos arqueológicos, forman parte hoy de la decoración del bar-restaurante del citado Museo local, en lugar de integrarse en un discurso museológico que hable al espectador de las arquitecturas y espacios urbanos en los que cumplían su función primigenia, así como de la importancia histórica que para Écija tuvo esta fuente ornamental, admirada -entre otros-, por Luis Vélez de Guevara en su Diablo Cojuelo ${ }^{10}$.

El Paseo de San Pablo, situado entre la ciudad y la margen izquierda del río Genil constituye uno de los lugares de esparcimiento ciudadano más antiguos de la provincia de Sevilla. Ordenado construir en 1578 por el municipio ecijano, estuvo adornado con ala- 
medas, jardines, fuentes y esculturas alegóricas, alcanzando gran esplendor durante la segunda mitad del siglo XVIII, cuando se construyeron los triunfos dedicados a San Pablo y a los Borbones. Las periódicas riadas y los momentos de incuria y abandono sufridos por este recinto lúdico han motivado una serie de continuas reconstrucciones que, al llegar a nuestros días, lo han transformado en un parque con escasa personalidad "I.

La arquitectura religiosa es otro de los grandes capítulos del patrimonio histórico ecijano. Por su monumentalidad, riqueza y capacidad, destacan los templos parroquiales. Casi todos poseen la estructura habitual de tres naves abovedadas, con cúpula sobre el crucero y capillas anexas, entre las que ocupa un lugar destacado la Capilla Sacramental. A este esquema responden las de Santa María, San Gil, Santa Cruz y Santa Bárbara, construidas en los siglos XVIII y XIX. La parroquia de Santiago, de estilo gótico mudéjar, mantiene -pese a las reformas sufridas en época barroca- su alfarje de madera original. Elementos muy singulares del paisaje ecijano son las afamadas torres barrocas 12, entre las que sobresalen las de San Juan, San Gil, Santiago, Santa Cruz y Santa María.

Los templos conventuales asumen la denominada planta de cajón rectangular. Los más sencillos son los de San José de las Teresas, Marroquíes y Santa Isabel, únicamente decorados con retablos (mayor y laterales). Esta tipología muestran, a su vez, las iglesias de los Hospitales de la Concepción y de San Sebastián. Incorporan un pequeño crucero con su cúpula las iglesias de Santa Inés, el Carmen y el Oratorio de San Felipe Neri. Mayor monumentalidad presentan las iglesias de la Merced, Carmelitas Descalzos, Santa Ana y Capuchinos, dotadas con capillas entre contrafuertes. Iglesias de convento con estructura parroquial (de tres naves con crucero) hallamos en los templos de San Francisco y Santo Domingo.

Dignos de señalar por su calidad son los alfarjes mudéjares de Santo Domingo, Marroquíes, la Concepción (Hospitalito) y Santa Isabel. También hay que nombrar las torres de la Concepción (Gemelas), el Carmen y Santa Ana, así como los campanarios de las Marroquíes, Santa Florentina, Santa Isabel, San Francisco, Descalzos y la Merced. Entre los interiores más suntuosos de la arquitectura andaluza del siglo XVIII hay que incluir la iglesia del convento de Carmelitas Descalzos de Écija. Se trata de un espacio unitario, dotado de un programa decorativo e iconográfico singular que conjuga una ornamentación de rica policromía a base de yeserías, con una buena colección de pinturas y retablos. Este templo único y espectacular se halla hoy en día cerrado al culto y en alarmante ruina.

En cuanto a edificios conventuales masculinos -todos desamortizados en el siglo XIX-hoy sólo podemos contemplar en gran parte de su integridad el que perteneciera a la Merced Calzada. Se conservan algunas dependencias residuales de los que fueran importantes complejos monásticos de San Francisco y Santo Domingo, así como de los del Carmen y
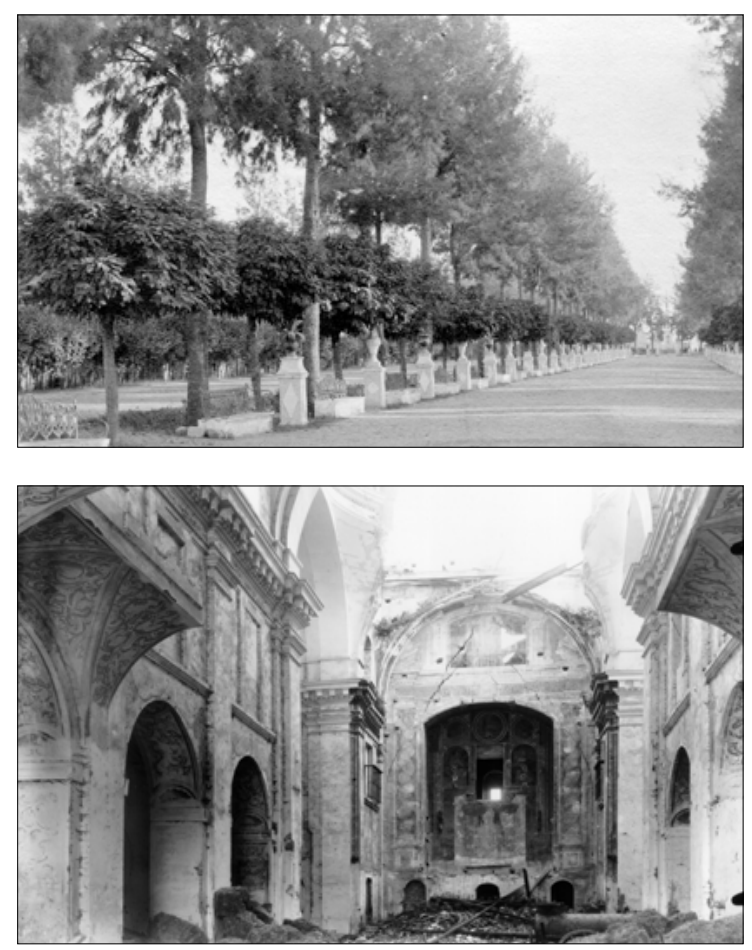

Fig. 4: Paseo de San Pablo. Principios del siglo XX

Fig. 5: Iglesia de la Concepción (Gemelas). en 1943 Foto: Laboratorio de Arte
Capuchinos. En 1946 fue derribada la iglesia conventual de los mercedarios descalzos de la Concepción (Gemelas) y en 1965 corrió la misma suerte la de los mínimos de la Victoria. En cambio, con desigual fortuna, las clausuras femeninas pueden apreciarse aún en Santa Florentina, Santa Inés (muy precariamente), San José de las Teresas y Santa Isabel, habiendo desaparecido prácticamente la del convento de las Marroquíes.

En otra categoría, debemos señalar la Ermita del Humilladero y un conjunto heterogéneo de capillas, altares y retablos callejeros ${ }^{13}$ de gran interés etnológico - destacando dos camarines construidos en 1726 y 1885 en honor de la patrona de Écija, la Virgen del Valle-. También hay que citar la Cilla del Cabildo, extenso edificio del siglo XVIII, que posee amplios graneros, almacenes y caballerizas.

El patrimonio mueble que atesora en la actualidad este cúmulo de edificios religiosos descrito es verdaderamente abrumador. La mayor parte de los templos citados poseen notables conjuntos retablísticos, entre los que destacan los de Santiago, Santa María, Santa Cruz, San Francisco, la Merced, Santo Domingo y los Descalzos. También son destacables los ejemplos pictóricos y escultóricos conservados en estos edificios, en especial aquellas imágenes que representan las principales devociones ecijanas-actuales y pretéritas-, como son la Virgen del Valle, Nuestra Señora del Rosario, los Nazarenos de San Juan, Santa Bárbara y Santa Cruz, los Crucificados de la Sangre, Expiración, Salud, Piedad y Confalón, así como el magnífico conjunto de esculturas de la hermandad del Santo Entierro y Nuestra Señora de la Soledad.

Capítulo aparte merecen las sillerías de coro parroquiales y conventuales ${ }^{14}$ y los numerosos objetos y enseres de mobiliario litúrgico de madera ${ }^{15}$, la vasta 
colección de ornamentos sagrados lujosamente bordados y las más de 800 piezas de orfebrería ${ }^{16}$ que aún enriquecen el patrimonio ecijano.

El patrimonio documental de Écija está formado por todos los documentos conservados en las diferentes instituciones públicas y privadas de la ciudad. En general, suelen mantener aceptable continuidad en sus series documentales y su estado de conservación es bastante bueno, salvo en el caso de los protocolos notariales. Por su relevancia, destaca primeramente el Archivo Municipal, cuyo fondo histórico constituye la mayor fuente de información para conocer la historia oficial de la ciudad; está compuesto de 10.483 unidades, abarcando el periodo histórico I263-200।. En fechas recientes, se han incorporado a la institución municipal dos fondos documentales de primer orden. El Archivo de la Contaduría de Hipotecas de Écija 17 es un valioso registro de todas las transacciones inmobiliarias y sus gravámenes realizadas en Écija y su partido judicial entre 1409 y 1862. El Archivo del Marqués de Peñaflor es un archivo familiar, perteneciente a la casa nobiliaria del mismo nombre, que está vinculada íntimamente a la historia de Écija desde época medieval; se compone de 715 unidades y sus límites cronológicos son 1293-1958.

El Archivo de Protocolos Notariales del Distrito de Écija es un fondo documental de gran riqueza informativa que resulta fundamental para reconstruir cualquier faceta de la historia de la ciudad. Es un registro de todas las escrituras públicas otorgadas ante los escribanos que, con nombramiento real, ejercieron sus oficios en Écija y Fuentes de Andalucía desde la Edad Media hasta 1900. Se compone de 4.4I 4 unidades y su registro más antiguo data del año |49|. Aunque se trata de un archivo privado, se halla precariamente instalado en unas dependencias municipales.

Los archivos eclesiásticos también tienen en Écija exponentes significativos. Destacan los Archivos Parroquiales de las seis parroquias históricas de la ciudad: Santa Cruz, Santa María, San Juan, Santa Bárbara, San Gil y Santiago. Constituyen una fuente básica para el estudio de la religiosidad, la demografía y la historia del arte ecijano. Entre todos suman 2.47 I unidades y se inician a comienzos del siglo XVI, o incluso a fines de la centuria anterior. El Archivo Parroquial de Santa María alberga, además el fondo perteneciente a la Vicaría Eclesiástica de Écija, el del Hospital de Niños Expósitos y el de la Universidad de Beneficiados de Écija, éste último con registros que datan de 1398. En los conventos de clausura, de difícil acceso, se conservan archivos, aunque sólo tenemos noticias del que existe en el de las Marroquíes.

\section{La tutela del patrimonio histórico. Análisis y propuestas}

Desde el punto de vista de la protección del patrimonio histórico, la ciudad de Écija posee desde 1966 la declaración como Conjunto Histórico Artís- tico, a la que actualmente se otorga la catalogación de Bien de Interés Cultural. En el ámbito urbano, también poseen esta consideración las iglesias de Santiago, la Concepción (Hospitalito) 18, el convento de San José de las Teresas, los palacios de los Marqueses de Peñaflor y de Benamejí y la Muralla que rodea la ciudad. En el término municipal tienen la máxima protección los castillos de Alhonoz y Alhocén, el recinto amurallado de la Isla del Castillo, el Torreón y la Torre de Gallape.

En total se trata de doce declaraciones de BIC, quizá insuficientes para un conjunto urbano de tamaño medio, aunque de riqueza patrimonial excepcional, como es el ecijano 19. Consideramos que existe un nivel adecuado de declaración con respecto a las incoaciones iniciadas, no obstante, es preciso señalar que, en la mayoría de los casos, se trata de expedientes de incoación antigua o incluso, de declaraciones colectivas producidas por el Decreto de 22-IV-I949 (BOE I25, de 5-mayo) que ordenó otorgar la consideración de monumento para todas los castillos, torreones, murallas, fuertes y fortificaciones del territorio nacional. Por este motivo, teniendo en cuenta las dimensiones y la monumentalidad del conjunto histórico de Écija, sería conveniente impulsar el ámbito de protección legal mediante la aprobación de nuevas incoaciones de inmuebles relevantes, con vistas a su declaración como BIC o para su inclusión en el Catálogo General del Patrimonio Histórico Andaluz.

Además, no debemos perder de vista que el espíritu de protección de la Ley del Patrimonio Histórico Andaluz es mucho más ambicioso que la legislación nacional (Ley 16/1985, de 25 de junio), al perseguir la protección individualizada de los bienes a través de su inclusión en el CGPHA mediante dos nuevas variedades de inscripción (genérica y específica) que comportan diferentes grados de protección.

En relación con la idea anterior, expresada ya en el preámbulo de la Ley I/1991, y al objeto de cumplir lo dispuesto por la Ley 16/1985 (art. 26.1), la Consejería de Cultura está elaborando el Inventario de Bienes Muebles de la Iglesia Católica que se conservan en los diferentes edificios religiosos ecijanos. Desde 1989 se halla finalizado, así mismo, el Inventario de Bienes Muebles de las Ermitas de la Provincia de Sevilla 20. Una vez concluido este proceso de inventariación podrá avanzarse un paso más, hasta lograr la catalogación de aquellos bienes merecedores de especial consideración, lo que redundará en el aumento de la protección del patrimonio histórico mueble ecijano. De hecho, en la actualidad no existe en Écija ningún bien mueble que posea la declaración de BIC.

El pasado día de 23 de enero ha sido aprobado definitivamente por la Consejería de Cultura el Plan Especial de Protección, Reforma Interior y Catálogo del Centro Histórico de Écija, que será el instrumento básico de referencia a la hora de establecer la ordenación y protección del ámbito delimitado en el Conjunto Histórico. Dicho instrumento de planeamiento ha catalogado en total 1.008 edificios de interés, 27 
espacios públicos, 20 elementos aislados y 2 jardines. Los inmuebles protegidos se distribuyen entre los siguientes niveles de protección: monumental (20), integral (9), global (64), tipológica (219), parcial (253), ambiental (406) y de la composición (37).

La conservación del patrimonio histórico ecijano tiene sus luces y sus sombras 21. La Ley I/1991, de 3 de julio, del Patrimonio Histórico de Andalucía previene que los titulares de la propiedad de los bienes integrantes del patrimonio histórico andaluz tienen la obligación de conservar, mantener y custodiar esos bienes, de manera que se garantice la salvaguardia de sus valores" (art. 15.I). Por otra parte, a los Ayuntamientos corresponde adoptar, en caso de urgencia, las medidas cautelares necesarias para preservar los bienes del Patrimonio Histórico Andaluz que se hallen en su término municipal y cuyo interés se encontrare amenazado (art. 4.1).

Pese a la norma citada, la realidad es que, en el apartado de la arquitectura civil ecijana, se aprecia hoy un alarmante proceso de abandono de las viviendas tradicionales que está provocando la rápida degradación de numerosas casas-patio. Los cambios de tipo socioeconómico que se vienen produciendo en el último cuarto de siglo, así como determinadas operaciones de tipo especulativo, han hecho que una parte significativa de la población opte por la elección de una residencia moderna, de nueva construcción, cuya conservación resulte fácil y asequible, pese a la significativa reducción de espacio y de prestaciones que ello supone y a la ubicación periférica de muchas de estas viviendas.

Este proceso lento pero imparable ha motivado la sustitución de numerosos inmuebles históricos, pese a las indicaciones -y a veces con el acuerdo- de la Comisión Provincial de Patrimonio Histórico. Sirvan de ejemplo el derribo en 2001 del inmueble $n^{\circ} 7$ de la calle Sor Ángela de la Cruz (vivienda cuya portada estaba fechada en 1698 y que poseía en su interior artesonados mudéjares, restos de un patio del siglo XVI y paramentos ricamente esgrafiados del siglo XVIII) y la desaparición en 1997 del más antiguo recinto hospitalario de Écija: el hospital de la Caridad y Niños Expósitos 22 (conjunto de edificaciones mudéjares y barrocas que conservaba la estructura y portada ojival de su capilla de fines del siglo $X V$, y de la que sólo se ha mantenido en pie la fachada exterior con los blasones de su fundadora, Beatriz Portocarrero, y una inscripción sobre piedra de 1602).

En precario estado de conservación se halla la casapalacio de la familia Pareja, edificio del siglo XVIII situado en la plazuela de Santa María, donde se ubica actualmente la comisaría de la Policía Nacional. Más inminente es el peligro de desaparición en que se encuentran el palacio de la familia Fernández de Bobadilla (c/. Sor Ángela de la Cruz n |4), la casa de la familia Muñoz Alarcón (sita en la barrera de Oñate) y las casas solariegas de los Zayas y los Montemayor (ambas fronteras al convento de Santo Domingo). Este último edificio es una casona de estilo gótico-mudéjar, construida a fines del siglo XV como
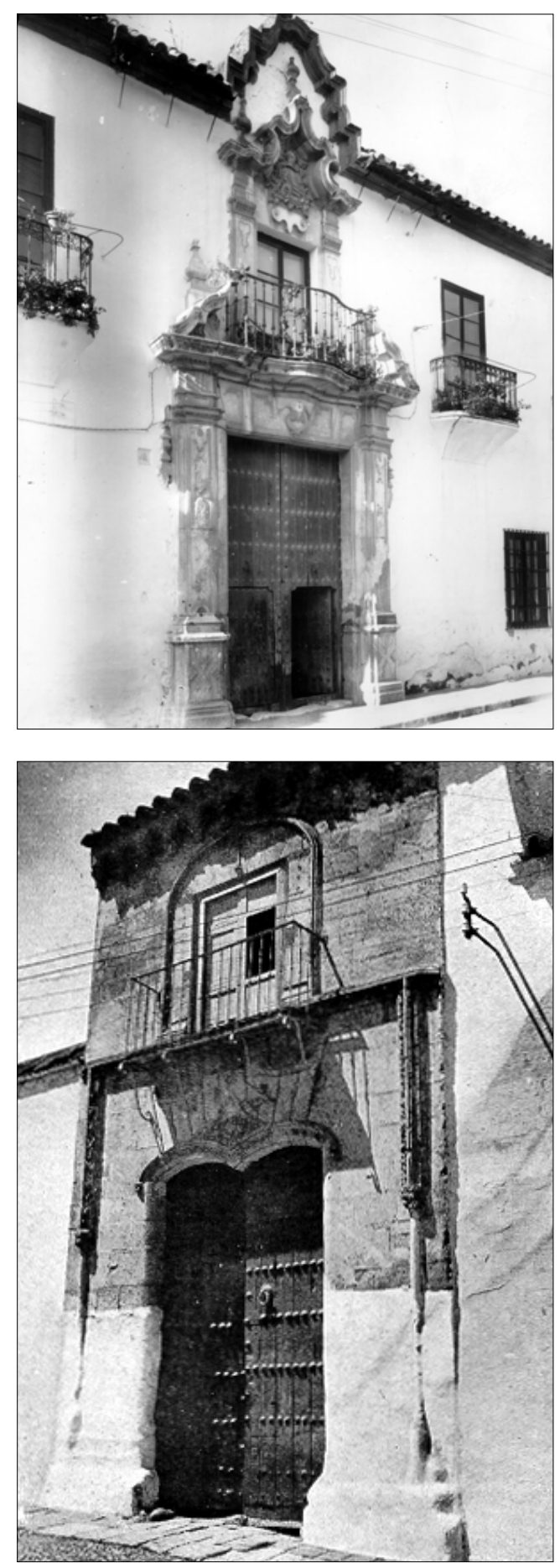

Fig. 6: Palacio de los Fernández de Bobadilla, en 1951

Fig. 7: Casa de Garci Sánchez de Badajoz, en 1950

Foto: Laboratorio de Arte sede del mayorazgo de Montemayor, en la que nació el poeta ecijano Garci Sánchez de Badajoz; la portada de piedra de esta casa fue desmontada y vendida en los años treinta del pasado siglo, desconociéndose su paradero en la actualidad ${ }^{23}$.

El Ayuntamiento de Écija y la Junta de Andalucía han llevado a cabo rehabilitaciones parciales en el palacio de Peñaflor, donde se halla instalada la Casa de la Cultura, en el palacio de Benamejí, sede del Museo Histórico Municipal, así como el Teatro Municipal. A su vez, se actúa en estos momentos sobre la antigua Plaza de Abastos, con vistas a la creación de un centro comercial. En el campo de la iniciativa estrictamente privada 

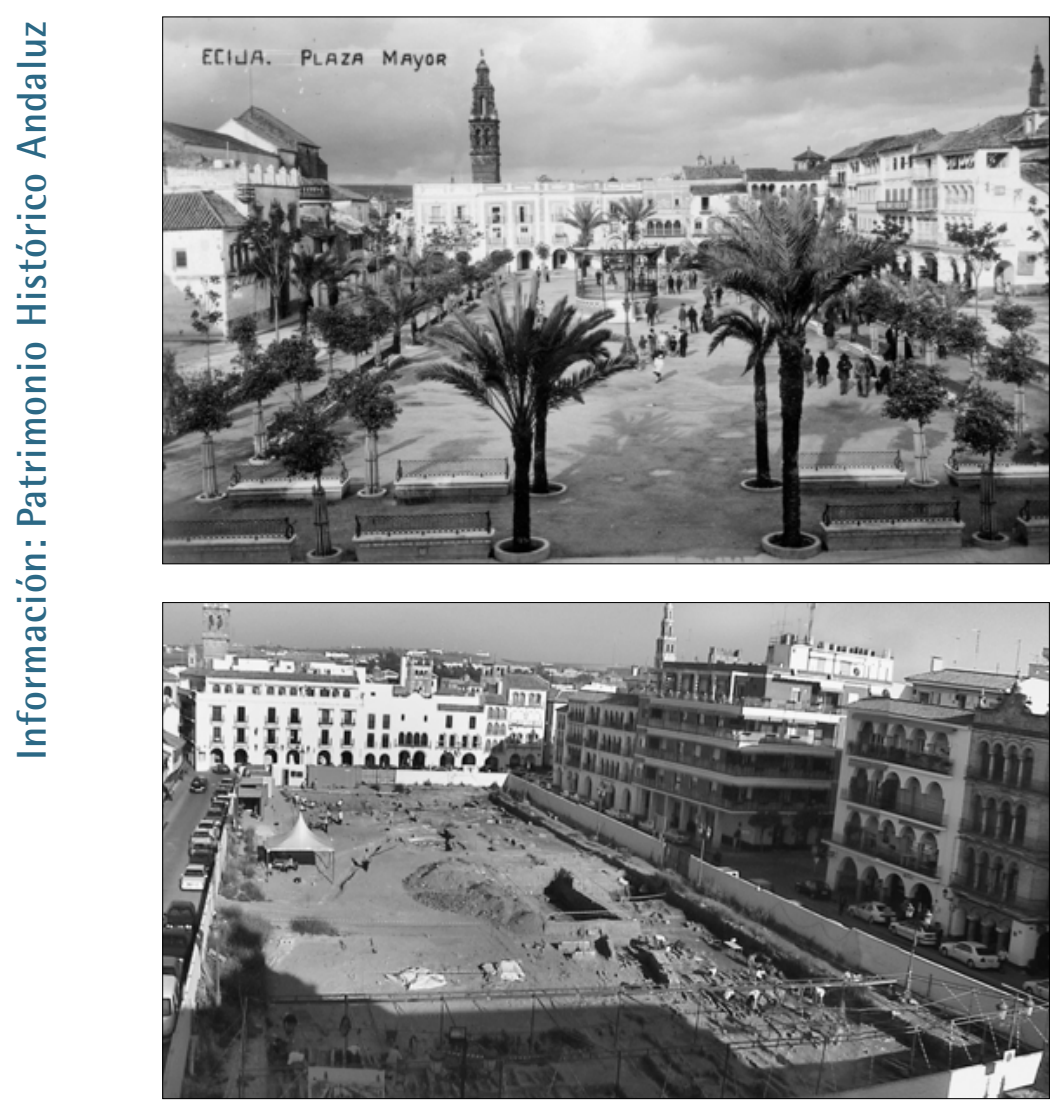

Fig. 8: Plaza Mayor, "El Salón". Hacia 1920

Fig. 9: Plaza Mayor, "El Salón”. 2002 Foto. Isabel Dugo también se han llevado a cabo loables esfuerzos para conservar interesantes ejemplares de la arquitectura doméstica local y, sobre todo, algunos de los más importantes palacios ecijanos. En este sentido, se han recuperado -con gran empeño por parte de sus propietarios- los palacios de Valhermoso de Cárdenas, de las Cuevas del Becerro, de la Garantía, del Conde del Águila, de Sauceda y de Almenara Alta. En la actualidad se halla pendiente de inicio la construcción de un grupo de viviendas en el recinto de la antigua Cárcel del Partido Judicial de Écija, de la que aún se mantienen en pie los muros exteriores y fachada.

A la hora de hablar de la conservación/destrucción del patrimonio histórico ecijano, no podemos dejar de citar el triste caso de la Plaza Mayor (popularmente conocida como "el Salón"). A raíz de la pretensión municipal de construir en su solar un aparcamiento subterráneo de tres plantas, pese a la oposición vecinal 24, la plaza fue cercada en 1998 a lo largo de todo su perímetro por un muro que ha hurtado su disfrute ciudadano desde entonces. Así mismo, esta obra faraónica destinada a lograr de un plumazo y -por decreto- la supuesta "modernización" de Écija, ha condenado a la subsistencia a gran parte del sector comercial de las inmediaciones y ha supuesto la destrucción de un ámbito tradicional de convivencia cívica que, a nuestro entender, también es una parte importante del patrimonio cultural ecijano. Por si estos fueran débiles argumentos, tememos que no se ha valorado suficientemente el incremento del tráfico que el aparcamiento atraerá al centro de la ciudad y sus repercusiones negativas sobre la conservación del conjunto histórico.
Poco tiempo después de cercar la plaza, fueron desmontados el mobiliario urbano y todas las especies vegetales que la adornaban, entre las que se hallaba un conjunto excepcional de palmeras -en su mayor parte centenarias- que constituían una de las señas de identidad más características y singulares de esta plaza ecijana. Tras la realización de las preceptivas catas arqueológicas $y$, ante la evidencia e importancia de los hallazgos realizados, desde 200 I se viene realizando una excavación extensiva del solar, con los resultados que ya hemos comentado.

Pero, sin lugar a dudas, el más olvidado de todos es el patrimonio histórico rural. La despoblación del campo y las transformaciones producidas en este medio durante los últimos treinta años han motivado la caída en desuso, casi absoluto, de la mayor parte de estas instalaciones. Cortijos y almazaras de los siglos XVII y XVIII, que unían a sus valores etnológicos la riqueza y el interés de sus tipologías arquitectónicas de carácter popular, han pasado a estar arruinados en muy breve espacio de tiempo o incluso han sido completamente arrasados (molinos de los Condes y las Caleras). En grave peligro de desaparición se hallan en estos momentos el cortijo de Quiñones (del que sólo resta la capilla) y las almazaras de la Rejana, Atalaya Alta, Mariscal, el Valle y las Monjas.

Las escasas muestras de arquitectura industrial existentes en Écija ya sólo son un recuerdo. En 1982 fue destruida por un incendio la fábrica de harinas "Nuestra Señora del Rosario", cuyas instalaciones dotadas con el "sistema Bhüler", habían sido inauguradas en 1912, a orillas del río Genil. Aún se mantienen en pie algunos muros de la Fábrica de Hielo -edificada sobre los antiguos batanejos-, las ruinas próximas de las aceñas, así como restos del conjunto hidroeléctrico de Cortés del Valle, donde se generó en 1897 la energía para el primer alumbrado eléctrico que tuvo Écija. El edificio mejor conservado es el molino harinero "La Giralda", levantado a comienzos del siglo XX junto al Genil, en las inmediaciones del cerro de la Concepción. Como ejemplo de la arquitectura en hierro, aún subsiste el Puente de Hierro, aguas abajo de la ciudad; construido poco antes de I 879 para la línea del ferrocarril, hoy se encuentra reutilizado para el tráfico de vehículos. De gran interés etnológico eran las norias y chirriones que se alzaban en las márgenes del Genil, algunas de las cuales todavía siguen cumpliendo sus funciones de regadío (p. ej. en el pago de Isla Redonda).

Como se desprende de todo lo que hemos visto hasta este punto, los recursos económicos destinados por instituciones públicas y privadas en aras de la recuperación del patrimonio civil han sido muy cuantiosos. Sin embargo, mucho mayores son los esfuerzos aunados para mantener el patrimonio religioso ecijano. En este capítulo, las acciones han partido, en la mayoría de los casos, de la administración central y autonómica, aunque tampoco han faltado tímidos apoyos del municipio y acciones de carácter ciudadano. En este sentido, se han restaurado las iglesias de Santiago, el Carmen, la Merced, la Concepción (Hospitalito), Santa Ana, Santo 
Domingo, Santa María, Santa Bárbara, San José de las Teresas (pendiente de una nueva fase de obras), San Francisco y San Gil. Desgraciadamente, alguna de estas restauraciones ha carecido del rigor y del respeto que semejante tipo de obras exigen; en concreto, en ésta última iglesia, durante las obras que se efectuaron en 1999, se desmanteló de forma caprichosa e injustificada el coro que existía en el centro de la nave principal y se destruyó un retablo de estucos de fines del siglo XVIII, dedicado a Nuestra Señora del Rosario, que ocupaba el trascoro. Ello ha motivado la incoación por parte de la Delegación Provincial de la Consejería de Cultura de un expediente sancionador 25 al promotor de la obra pero, en definitiva, nos hallamos ante un hecho irreversible que constituye un caso flagrante de destrucción del patrimonio histórico, al que nadie ha puesto remedio.

Por último, no podemos dejar de mencionar -y de denunciar- que permanecen en lamentable estado de conservación la iglesia de los Descalzos (cerrada al culto y ruinosa), la capilla de Belén (en ruinas), el claustro del convento de Santa Inés (en ruinas y apuntalado por la Consejería de Cultura, como obra de emergencia, desde 1990), el hospital de San Juan de Dios (amenazado por la construcción entre sus muros de una promoción de viviendas unifamiliares) y los campanarios de la Victoria, San Juan, Santa María, Santa Cruz, Santa Florentina, Santo Domingo y las torres de la Concepción (Gemelas).

El patrimonio mueble religioso presenta algunas deficiencias en su conservación, motivadas en parte por el uso continuado al que siguen estando sometidos aún gran parte de los enseres litúrgicos de las iglesias ecijanas. También son numerosos los retablos, esculturas y pinturas que precisan ciertas intervenciones. Lo más preocupante son algunos graves incidentes aislados de expolios -retablos barrocos de la iglesia del convento de la Victoria, desmontados y llevados de Écija hace unos treinta años, para revestir la iglesia del castillo de Aracena- y robos -imagen del Dulce Nombre de Jesús y Viril de plata dorada y piedras preciosas, de la parroquia de Santa María-. Innumerables han sido los casos de ventas, más o menos controladas, de variadísimos objetos artísticos relacionados con el culto religioso: esculturas, pinturas, bordados, piezas de orfebrería, mobiliario (de madera, forja y bronce), libros corales, documentos, etc., que se conservaban en los conventos de clausura, parroquias y hermandades; entre estos objetos podemos citar, por ejemplo, la venta en 1967 de la cruz de plata y carey 26 ( 1735) del Nazareno de la iglesia de San Juan y la reciente venta de un camarín rococó ${ }^{27}$ que existía en el convento de Santa Florentina.

En el terreno del patrimonio documental existe una asignatura pendiente que, de no remediarse pronto, puede suponer una pérdida irreparable para la cultura ecijana y andaluza en general. Nos referimos al ya mencionado Archivo de Protocolos Notariales del Distrito de Écija, cuya deplorable situación viene siendo denunciada públicamente desde 199728 . El estado actual de conservación de este fondo documental es muy deficiente, por cuanto se halla instalado sobre estanterías de madera y en unas dependencias con alto grado de humedad y escasa ventilación, situadas en la planta baja del palacio de Peñaflor; además, sufre el ataque generalizado de una plaga de insectos xilófagos que, a medio plazo, puede suponer la destrucción irreversible de uno de los fondos documentales más valiosos de la provincia de Sevilla.

La investigación y difusión es otro de los grandes capítulos de la tutela del patrimonio ecijano. La primera de estas tareas viene desarrollándose a buen ritmo desde los últimos años. La obligatoriedad de efectuar catas arqueológicas en las obras que, afectando al subsuelo, se promueven en el casco antiguo protegido de Écija ha proporcionado un caudal de información y materiales que está abriendo nuevas vías a la investigación y al conocimiento del pasado de la ciudad. En este sentido, están siendo decisivos los descubrimientos que cada nuevo día se realizan en la excavación extensiva de la Plaza Mayor y el Picadero. En 200 I se han localizado en las inmediaciones del puente sobre el Genil los restos del Rollo de Écija, que había sido derribado durante el periodo revolucionario de 1868. Instalado en este lugar desde mediados del siglo XVI, se componía de un pedestal con gradas que soportaba un fragmento de un gran fuste de granito de origen romano (que es el ahora recuperado); esta columna se remataba con una pieza cuadrangular para los garfios y un león de piedra con las armas de la ciudad. Con este hallazgo, la ciudad de Écija pasa a contar con un nuevo $\mathrm{BIC}$, puesto que estos restos están incluidos en el Decreto 57//1963, de 14 de marzo (BOE de

Fig. 10: Coro de la Iglesia de San Gil. 1998

Fig. I I: Iglesia de San Gil. Tras el desmantelamiento del coro. 1999
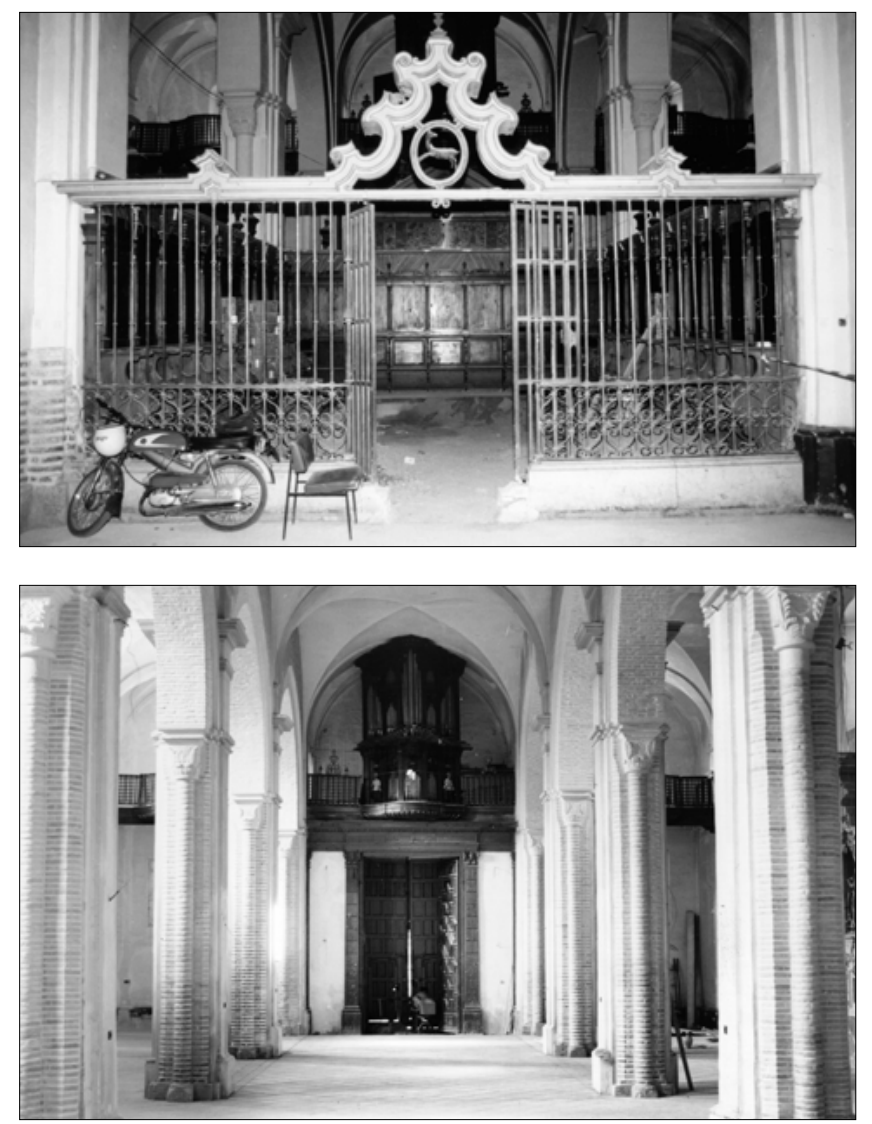


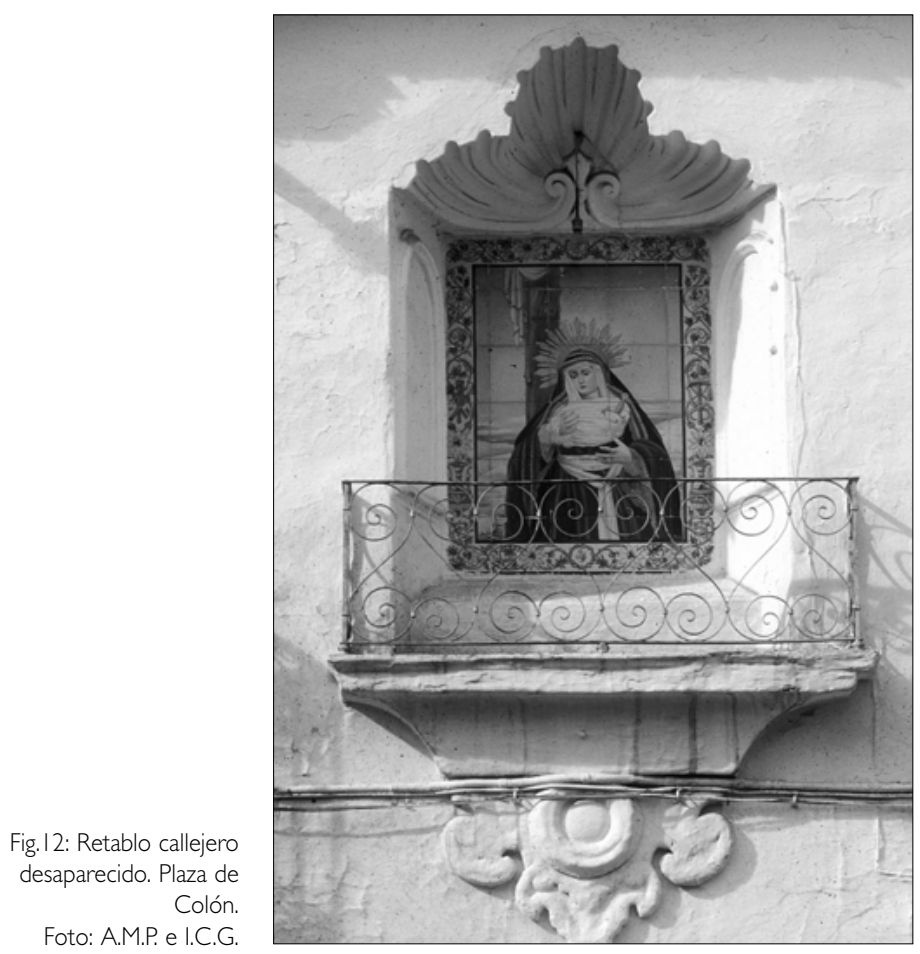

30-3-1963), que dispone la protección de los escudos, emblemas, piedras heráldicas, rollos de justicia, cruces de término y piezas similares de interés artístico. El contenido de este Decreto ha sido recogido por la Disposición Adicional segunda de la Ley 16/1985, del Patrimonio Histórico Español.

Desde 1992, y con impulso de la Universidad de SeviIla, se viene desarrollando un proyecto de investigación cuya finalidad es la realización de un estudio pluridisciplinar sobre la evolución histórica de la ordenación territorial y del paisaje de Écija. La elección del ámbito geográfico ecijano estuvo condicionada por tratarse de un núcleo fundamental en el poblamiento de la zona meridional hispana desde época prerromana, que podía ser objeto de unas posibilidades de estudio verdaderamente notables. La principal aportación de este ambicioso proyecto a la gestión y protección del patrimonio histórico local ha consistido en la elaboración de la Carta Arqueológica Municipal, entendida como eficaz instrumento del planeamiento, así como la redacción de una Carta de Riesgo del Municipio de Écija 29.

Por otro lado, bajo el patrocinio municipal, se han celebrado entre 1986 y 200 I seis Congresos de Historia sobre diversos aspectos de la historia y el patrimonio ecijanos, abarcando desde la prehistoria hasta nuestros días ${ }^{30}$. Dentro de este apartado, debemos citar las numerosas tesis doctorales y trabajos de investigación que, desde el ámbito universitario, han venido estudiando diferentes facetas de la historia -colección diplomática medieval, época de los Reyes Católicos, ordenanzas municipales del siglo $\mathrm{XVI}$, vicaría eclesiástica, beneficencia y hospitalidad durante el siglo XIX-y el patrimonio ecijanos -arqueología, escultura, pintura, arquitectura y urbanismo, arte de la madera, orfebrería, etc-.
En 1997 tuvo lugar la creación del Boletín de la Real Academia de Ciencias, Bellas Artes y Buenas Letras "Luis Vélez de Guevara", bajo patrocinio de dicha institución ecijana. Esta publicación nació con la idea de acoger cuantos estudios de carácter histórico, artístico, literario o científico, tuvieran como objeto a la ciudad de Écija o su comarca, reservándose un apartado destinado a la creación literaria y otro, a reseñas bibliográficas; hasta la fecha se han publicado cuatro números de este boletín.

En el campo de la difusión, el Ayuntamiento, con el apoyo de otras entidades e instituciones, ha organizado periódicamente exposiciones sobre las más variadas facetas del patrimonio ecijano (arqueología, arquitectura, escultura, pintura, orfebrería, tejidos bordados, documentos y fotografías), utilizando las salas que para este efecto se hallan habilitadas en los palacios de Peñaflor y Benamejí, así como en la propia Sala Capitular del consistorio. Además, se han publicado las actas de los Congresos citados y numerosas monografías de carácter científico provenientes del ámbito universitario. En 2001 ha aparecido el primer número de la revista Astigi Vetus, patrocinada por la Fundación Museo Histórico Municipal de Écija. Se trata de una publicación de carácter anual, destinada al ámbito científico, con secciones sobre Teoría y método y Arqueología de Écija y su comarca; su objetivo principal es la difusión de las actividades arqueológicas desarrolladas en Écija y su comarca, así como de la riqueza y variedad de su patrimonio histórico, aunque no se descartan colaboraciones que por su interés y valía excedan el ámbito local.

En cuanto al sector privado, existe desde 1997 una empresa que presta servicios turísticos; se denomina Ecitur, está formada por profesionales del patrimonio y ofrece visitas guiadas especializadas, ocupándose también de la organización de jornadas y viajes culturales. Esta sociedad cooperativa está homologada por la Junta de Andalucía para impartir cursos de formación ocupacional, hallándose en marcha actualmente un Curso de Agentes de Desarrollo Turístico.

Como decíamos al principio, un mayor aprecio colectivo provoca el incremento de la protección del patrimonio; en suma, es necesario aumentar la valoración social del patrimonio. Una forma de conseguir este propósito es llevar a la práctica el llamado "proceso de musealización de la ciudad", pero no entendido como un proceso de embalsamamiento de algo muerto e inútil, que sólo se conserva para la observación de los especialistas ${ }^{31}$. La conservación de la riqueza patrimonial de Écija debe estar armonizada con su reactivación socio-económica y, de hecho, esa puede ser la clave para garantizar su logro. La definición "museo fuera del museo" es perfectamente aplicable a Écija, donde gran parte de la vida ciudadana se desenvuelve íntimamente vinculada a un número considerable de bienes culturales que aún mantienen su uso original y conservan la razón de ser que les dio origen.

La puesta en valor de este patrimonio supone el uso y disfrute del mismo por parte de todos los ciuda- 
danos. Pero esa puesta en valor requiere un proceso de interpretación, de presentación, de acercamiento, de conocimiento. Como afirma Jorge Morales, es misión de las instituciones fomentar la interpretación del patrimonio pues, además de los beneficios educativos y formadores de la población, a largo plazo, verán mejorada su imagen pública ${ }^{32}$.

En la actualidad, el Museo Histórico Municipal de Écija posee unos contenidos eminentemente arqueológicos; puesto que existe el proyecto de ampliar sus fondos a otras parcelas del patrimonio y de la historia (hasta llegar a nuestros días), bien podría erigirse como el organismo local idóneo al que encomendar esta tarea de interpretación del patrimonio histórico en todas sus facetas. Mediante la coordinación de las actividades de difusión y puesta en valor, se convertiría en cabecera de un sistema o red de lugares musealizados dotados de su propia infraestructura.

Entre las posibilidades de actuación podríamos señalar la propuesta de itinerarios guiados, urbanos o rurales, en función de los valores más señalados de los bienes culturales: naturales, históricos, artísticos, etnológicos, etc. También debería controlar la formación de las personas que actúen como guías-intérpretes del patrimonio histórico, así como tener competencia en el diseño, redacción y edición de los materiales de difusión: carteles, señales, folletos, guías y medios audiovisuales.

Como medida positiva y de fomento que ya está repercutiendo favorablemente sobre la conservación y puesta en valor del patrimonio histórico local, hay que citar que el Ayuntamiento de Écija, en su Ordenanza Reguladora del Impuesto sobre Construcciones, Instalaciones y Obras (BOPS n 251, de 29-X199), contempla la bonificación en diferentes porcentajes del citado impuesto en las obras "declaradas de especial interés o interés municipal por concurrir circunstancias sociales e histórico-artísticas" (art. 7.la). Otro estímulo beneficioso para la preservación del patrimonio es la exención del Impuesto de Bienes Inmuebles a la que últimamente se vienen acogiendo ciertos edificios históricos, con arreglo a lo prescrito por la Ley Reguladora de las Haciendas Locales (Ley 39/1988, de 28 de diciembre, art.78.2).

En Écija es necesario fomentar la revalorización del patrimonio y desterrar de una vez por todas el razonamiento que asocia los valores históricos o monumentales con insuperables trabas administrativas y obstáculos al desarrollo y al progreso; iniciativas como la emprendida por la familia Palma-Gastón son claro ejemplo de cuanto afirmamos. Estos ecijanos son propietarios actuales del que fuera palacio de los marqueses de las Cuevas del Becerro, situado en la calle Espíritu Santo $n^{\circ} 10$, junto a la parroquia mayor de Santa Cruz. Desde 2001 han abierto su casa a la visita pública, la cual se realiza con acompañamiento guiado, con un horario regular y con un precio bastante módico.

El palacio del marqués de las Cuevas del Becerro es uno de los típicos palacios dieciochescos, tan carac-

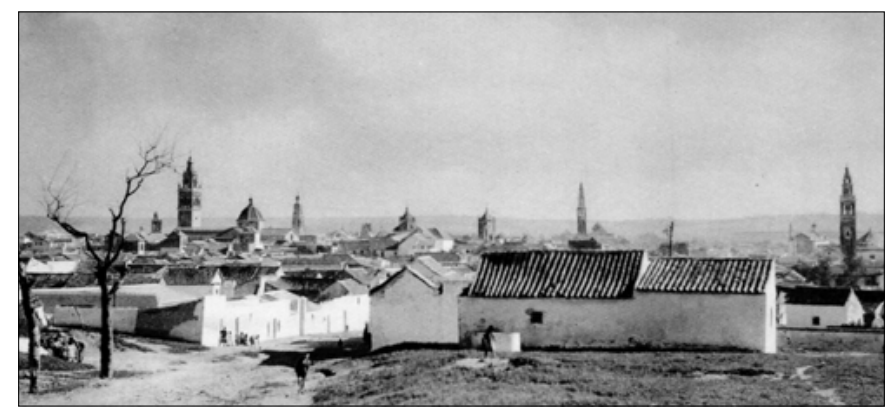

terísticos de esta ciudad, aunque posee vestigios de épocas anteriores, tal vez procedentes del desapare-

Fig. 13: Vista parcial de Écija. Hacia 1950 cido convento de monjas dominicas del Espíritu Santo, que se hallaba en el solar vecino. El palacio está dotado de las señas de identidad habituales: portada pétrea blasonada y suntuosa, balcón corrido al gusto ecijano, apeadero, escalera monumental abovedada, estancias cubiertas con importantes alfarjes mudéjares, patio principal con arcos sobre columnas, caballerizas, jardines y zonas de servicios. Todas estas dependencias poseen el mobiliario propio de una vivienda de este rango que, si bien no es el original del siglo XVIII, contiene en cambio piezas muy destacables de pinturas, grabados, esculturas, tapices, bargueños, etc. Por cierto, este edificio que reúne todas las condiciones para ser declarado BIC, carece en estos momentos de protección legal, hallándose únicamente catalogado por el Plan Especial con el máximo nivel de protección (monumental).

En suma, se trata de un conjunto patrimonial bastante completo, cuya contemplación permite al espectador un conocimiento muy directo de lo que pudo ser la residencia y la forma de vida de una de las muchas familias que componían la nobleza terrateniente ecijana a mediados del siglo XVIII, o sea, en el momento de máximo esplendor de la ciudad. Esa misma nobleza que obtenía su riqueza de las rentas vitalicias que le proporcionaba la jurisdicción señorial, de los grandes rebaños de ganado $y$, sobre todo, de los recursos agrícolas que generaban los inmensos territorios que formaban sus mayorazgos. Nobleza que, gracias a esas riquezas, construía los palacios, presidía las hermandades, costeaba los retablos de las parroquias y conventos, integraba el cabildo municipal o participaba en las visitas y proclamas reales.

Nos hallamos, por tanto, ante un magnífico caso práctico de puesta en valor del patrimonio histórico, cuyas posibilidades no están suficientemente aprovechadas ni difundidas, pues ni siquiera hallamos en Écija algún cartel o indicador que informe al visitante de la existencia del palacio en cuestión. Únicamente el Museo Histórico Municipal y la Oficina Municipal de Turismo distribuyen folletos informativos al respecto. Experiencias similares podrían llevarse a cabo en algunos de los palacios ecijanos que todavía mantienen parte de su esplendor original, así como en las diferentes parroquias y en algunos conventos de clausura. A este respecto, hemos de citar que el convento de San José de las Teresas, antiguo palacio mudéjar de los condes de Palma (obra excepcional 
del siglo XIV), pese a estar declarado BIC desde 1931, se halla cerrado completamente a las visitas y es desconocido por la mayoría de los ecijanos.

Actividades de interpretación y puesta en valor del patrimonio, con relación a las actividades ciudadanas, también podrían llevarse a cabo utilizando lo que aún se conserva del edificio de las Carnicerías Reales, del Pósito, del Arca Real del Agua, del Mercado de Abastos, de la Cárcel del Partido o de la Cilla del Cabildo. Los valores del patrimonio natural y etnológico se pueden transmitir mediante recorridos documentados a lo largo del río Genil, analizando su influencia sobre la ciudad, en especial en el ámbito del Paseo de San Pablo y el puente, e inci-

\section{Notas}

I. SAN MARTíN, Concha. "La protección del patrimonio arqueológico desde el museo. Criterios de difusión". Difusión del Patrimonio Histórico, Sevilla, 1996, pp. 28-37.

2. Téngase en cuenta que, por esos años, la ciudad de Córdoba tenía 48.000 habitantes, y la de Sevilla rondaba los 65.000.

3. RODRÍGUEZ TEMIÑNO, Ignacio. "La gestión del patrimonio arqueológico en Écija" Actas del V Congreso de Historia "Écija en la Edad Contemporánea", Écija, 2000, pp. 193-207.

4. "Hallan en Écija una estatua romana aún policromada", Diario de Sevilla, 9-II-2002

5. Écija. Avance del Plan Especial de Protección, Reforma Interior y Catálogo del Centro Histórico. Málaga, 1988, p. 25.

6. LÓPEZ JIMÉNEZ, Clemente M. Transformaciones urbanas en Écija. |808-1868. Écija, 1991.

7. Sobre este edificio, véase MARTíN OJEDA, Marina; VALSECA CASTILLO, Ana. Écija y el Marquesado de Peñaflor, de Cortes de Graena y de Quintana de las Torres. Córdoba, 2000.

8. Ibidem.

9. HERNÁNDEZ LEÓN, Elodia; QUINTERO MORÓN, Victoria. "Un recurso olvidado: metodología para el estudio del patrimonio etnológico en la campiña ecijana" Actas del V Congreso de Historia "Écija en la Edad Contemporánea", Écija, 2000, pp. 209-2I4.

I0. GARCÍA LEÓN, Gerardo. "La Fuente de las Ninfas de Écija". Revista Archivo Hispalense, no 221 Sevilla, 1989, pp. 153-172. Otros fragmentos de la Fuente de las Ninfas se hallan en el parque Luis Vélez de Guevara (taza y pedestales), la parroquia de Santa Cruz (Neptuno) y la Colección Arqueológica de Santa María (cabezas de dos Ninfas).

II. AGUILAR DIOSDADO, Abilio; GARCíA LEÓN, Gerardo. Reseña Histórica del Paseo de San Pablo de Écija, Écija, 1988. Las últimas reformas del Paseo han arrasado lo que restaba de la primitiva organización y han motivado la desaparición de numerosos restos de columnas de jaspe y granito que aún se conservaban diseminados por los jardines.

12. VALSECA CASTILLO, Ana. Arte Hispalense. De las torres parroquiales de Écija en el siglo XVIII., Sevilla, 1996.

13. MARTíN PRADAS, Antonio y CARRASCO GÓMEZ, Inmaculada: Manifestaciones de la religiosidad popular en el callejero ecijano. Écija, 1993.

14. MARTÍN PRADAS, Antonio. Las sillerías de coro en parroquias y conventos ecijanos. Écija, 1993.

15. FERNÁNDEZ MARTÍN, Mercedes. El arte de la madera en Écija durante el siglo XVIII. Écija, 1994.

16. GARCÍA LEÓN, Gerardo. El arte de la platería en Écija. Siglos XV-XIX. Sevilla, 200I.

17. Se compone de 113 unidades. MARTíN OJEDA, Marina: GARCÍA LEÓN, Gerardo. "El archivo de la Contadunía de Hipotecas de Écija". Archivo Hispalense, n² 227, Sevilla, 1991, pp. 27-45.

18. En estos momentos, el decreto para la declaración como BIC de esta iglesia se halla en fase de aprobación. diendo sobre los molinos, aceñas, norias y las huertas del entorno urbano de Écija.

Para concluir, queremos insistir en la idea de que el patrimonio histórico de Écija puede ser más valorado y disfrutado por los ciudadanos y que es preciso aprovechar mucho más ese caudal de información que, durante los últimos veinte años, está proporcionando la investigación científica llevada a cabo sobre la ciudad y sus múltiples vertientes. Porque la puesta en valor del patrimonio debe basarse forzosamente en una investigación cualificada, que ofrezca una información veraz y contrastada. En definitiva, hoy sabemos mucho más sobre Écija; nos resta hacer accesible y apetecible ese conocimiento a la sociedad.
19. La vecina ciudad de Carmona, con un rico patrimonio, proporcionalmente comparable al ecijano, posee la declaración de $\mathrm{BIC}$ para 23 de sus monumentos.

20. HERNÁNDEZ NÚÑEZ, Juan Carlos. "Algunas reflexiones sobre las ermitas de la provincia de Sevilla y sus bienes muebles". Boletín del Instituto Andaluz de Patrimonio Histórico, n 33.. Cádiz, 2000, pp. 183-191.

21. GONZÁLEZ GÓMEZ, Juan Miguel. "Reflexiones en torno a la conservación y restauración de los bienes culturales de Écija". Boletín de Bellas Artes. Sevilla, 200I, pp. |57-I7|.

22. GARCÍA LEÓN, Gerardo. "El Hospital de la Caridad y Crianza Niños Expósitos de Écija". Actas del II Congreso de Historia "Écija en el siglo XVIII", Écija, 1995, pp. 309-320.

23. HERNÁNEZ DÍAZ, José; SANCHO CORBACHO, Antonio: COLLANTES DE TERÁN, Francisco. Catálogo Arqueológico y Artístico de la Provincia de Sevilla, tomo III, Sevilla, 1950, p. 234,

24. "Vecinos de Écija piden el respaldo de la Junta contra un aparcamiento", El País, I7-I-1999. "La Junta asegura que no ha autorizado el párking del Salón", El Correo de Andalucía, |4-I-1999.

25. "Desmantelado ilegalmente el coro de la iglesia de San Gil de Écija", Diario ABC, 30-IX-1999. "La Junta sanciona a la iglesia de San Gil por desmontar el retablo", Diario de Andalucía, 28-XI-1999.

26. GARCÍA LEÓN, Gerardo. "La Cruz de las Penas de San Vicente". Revista Laboratorio de Arte, nº 6. Sevilla, 1993, pp.

27. "Cultura no frenará la venta de un camarín del XVIII", Diario de Sevilla, I0-III-1999. "El Ayuntamiento de Écija cree un expolio la venta del camarín a los Gitanos", Diario ABC, | | -|||- 1999

28. La penosa situación de este Archivo ha sido denunciada en la prensa en varias ocasiones: "Cultura realizará una inspección en la sección histórica del Archivo de Protocolos de Éciija", El Correo de Andalucía, 5-XI-1997; “Un informe de Cultura reconoce el pésimo estado de conservación de los Protocolos de Écija", El Correo de Andalucía, 4-V-1998.

29. SÁEZ FERNÁNDEZ, Pedro; ORDÓÑEZ AGULLA, Salvador; GARCÍA VARGAS, Enrique; GARCÍA-DILS DE LA VEGA, Sergio. "Aplicaciones de los S.I.G. al territorio y casco urbano de Écija (Sevilla) (Proyecto AstiGIS)". Astigi Vetus. Revista del Museo Histórico Municipal de Écija, n I, Córdoba, 200 I, pp. 105-I I 8.

30. Se hallan publicadas las actas de los cinco primeros congresos de historia. Acaban de presentante las actas del Congreso Internacional "Ex Amphora Baética", publicadas conjuntamente por el Ayuntamiento de Écija y la Universidad de Sevilla. En prensa se encuentran las actas del VI Congreso de Hisotira "Écija y el Nuevo Mundo", celebrado en noviembre de 2001.

3I. MINISSI, Franco. "Musealización y vitalización de la ciudad". Reflexiones sobre Centros Históricos. Córdoba, 1994, pp. 1 22- 127.

32. MORALES MIRANDA, Jorge. "La interpretación del patrimonio natural y cultural: todo un camino por recorrer". Boletín del Instituto Andaluz de Patrimonio Histórico, $n^{\circ}$ 25. Cádiz, 1998, pp. I50- 157. 